Sharif University of Technology
Scientia Iranica
SCIENTIA

Research Note

\title{
Short free-standing pole LED luminaire and lens design for road lighting
}

\author{
İ.S. Ünc ̈̈ ${ }^{\mathrm{a}}$ and M. Kayakuş \\ a. Department of Electrical and Electronics Engineering, Faculty of Technology, Isparta University of Applied Sciences, Isparta, \\ Turkey. \\ b. Department of Business Informatics, Faculty of Social Sciences and Humanities, Akdeniz University, Antalya, Turkey.
}

Received 18 April 2020; received in revised form 16 November 2020; accepted 24 May 2021

\section{KEYWORDS \\ Optics design; \\ Lighting; \\ Road lighting; \\ LED; \\ Luminaire design.}

\begin{abstract}
Road luminaries are required to provide a certain quality of luminance that meets the standards and existing road characteristics. For this reason, the light from the light source should be directed in the desired conditions. Although a range of minimum average road surface luminance recommended for different classes of road is concurrently provided, the priority is to ensure that they are economical. In this study, a freeform lens and LED luminaire design with high luminous efficacy, low glare, and uniform luminance distribution with a height of $1.5 \mathrm{~m}$ and a distance of $7 \mathrm{~m}$ between poles were designed for M3 road standards. First, lens design was made by using optical and illumination design software. Furthermore, lens manufacturing and luminaire production were the result of the success of the design simulation test. The success of the Light Emitting Diod (LED) luminaire in meeting Commision Internationale de l'éclairage (CIE) standards in the designed road was evaluated. In addition, the advantages and disadvantages were determined in comparison to High Pressure Sodium (HPS) vapor lamps.

(C) 2022 Sharif University of Technology. All rights reserved.
\end{abstract}

\section{Introduction}

The energy dedicated to road lighting is increasing day by day. Lighting represents $15-20 \%$ of the world yearly electricity [1]. Public (predominantly street) lighting contributes $2.3 \%$ to the global electricity consumption [2]. Many studies have been carried out to evaluate road lighting in terms of energy efficiency due to these high energy requirements and costs [3-8].

In the selection of the lamp to be used in road lighting, luminous efficacy, life, and luminous flux must be considered. High Pressure Sodium (HPS) luminaires

*. Corresponding author. Tel.: +905062654830 E-mail addresses: serkanuncu@isparta.edu.tr (i.S. Üncü); mehmetkayakus@akdeniz.edu.tr (M. Kayakuş)

doi: $10.24200 /$ sci.2021.55819.4421 have been widely used for road lighting because of their high efficacy. However, it is impossible to control all the light rays emitted from a large-sized HPS source within the effective region, resulting in light pollution and energy waste [9]. Lighting technologies based on Light Emitting Diodes (LEDs) are a promising innovation for street lighting [10]. The rapid development of LEDs, especially their increasing luminous efficacy, makes them a viable light source offering potential for energy saving. LEDs also provide other advantages such as reduced maintenance costs, longer service life, the possibility to control the illumination levels, and reduced light pollution. However, LED lighting still has some disadvantages. The lack of standardization, temperature dependence, and high price of the luminaires restrict their applicability and wider adoption in road lighting applications. In addition, the technical data provided by the seller or manufacturer of the lu- 
minaire are often inadequate to make a comprehensive comparison [11].

There are many LED luminaire models used in road lighting. Each LED luminaire has its own advantages and disadvantages. The most important features of LED luminaires are the lens or reflector parts of the luminaires. Standard lenses and reflectors are used in the market for LED luminaires to be used in lighting. Companies do not prefer to produce original lenses or reflectors for each project. Ding et al. [12] stated that in order to achieve the targets in lighting design projects, the distribution of the light flux from the LED should be done again.

LEDs cannot provide the required density distribution on their own. In order to achieve the targeted lighting distribution with LEDs, the density distributions must be used with a secondary lens [13-17]. Wang et al. [18] mentioned the importance of using secondary optics in LED applications. The light distributions of the LED cannot directly meet the requirements of specific applications; it has uneven light distribution curves. Secondary optical (free-form lens) is an optical technology that provides high design freedom in LED luminaire applications as well as lighting control in LED lighting design [19-23].

A standard street lamp should be highly efficient and provide low glare to protect drivers from danger. Nowadays, it is recommended that a secondary lens is used to provide these conditions [9,24-27]. Wang et al. [25] designed a smooth free-form lens that controls the intensity of street lighting to reduce glare. Lee et al. [26] designed a luminaire possessing a cluster of LEDs with Total Internal Reflection (TIR) lenses that are put inside a reflective box for high optical efficiency, high optical utilization factor, and low glare and they illuminate the street with high uniformity. In addition, much work is done to improve the operating performance of LEDs [28,29].

In this study, designing and manufacturing of LED luminaire with high efficiency factor, low glare rate, and homogeneous light distribution were performed for international M3 road standards. In the case of placement of luminaires on the road, LED luminaries with $1.5 \mathrm{~m}$ height are placed 7 meters side by side and 7 meters mutually on the road, as shown in Figure 1.

\section{Method}

Optical design programs are used in lens design. These programs simulate the light distribution of the lens by calculating the movement of light. Design results can be tested and optimized before production. Thus, a significant amount of time and money can be saved according to the trial-and-error method. Zemax, Lighttools, ASAP, Trace Pro, Photopia, and Optisworks

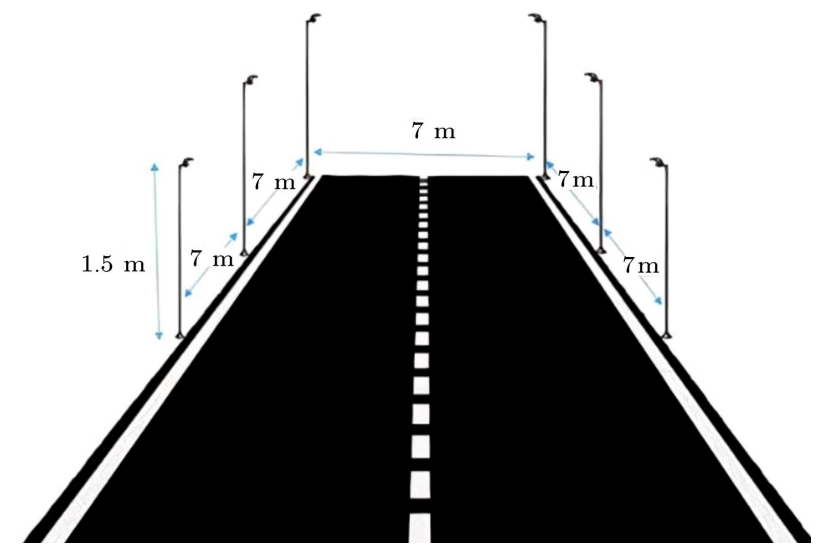

Figure 1. Placement of luminaires on the road.

lighting optics are some of the optical design programs that can be designed.

The LED luminaire is intended to be the most ideal in terms of energy consumption, efficiency factor, lamp life, color rendering, low glare, and maintenance coefficient. In the first stage, the optical lens design for road lighting was done by using Zemax software. In the second stage, prototype lens mold was produced and six lenses were manufactured using this mold. In the third stage, LED luminaires were manufactured for road lighting by using produced lenses and supplied armature equipment (LED module, coolant surface, and LED driver circuit).

\subsection{Lens design for LED luminaires}

First, the brand and model of the LED to be used are determined and the light distribution file of this LED is defined as the light source in Zemax. In this study, high-power Acrich-series LEDs of Seoul semiconductor were used. Optical design in Zemax lighting design program is done in two different design modes: sequential and non-sequential modes. In this study, lens design was performed in the non-sequential mode. In the nonsequential mode, the positions and axes of objects can be different. The light emitted from the light source is reflected or broken through these objects and it reaches the defined detector. These detectors allow predicting how the optical design creates a light distribution.

The measurement results in Zemax program include light intensity and spectrum distribution in a polar coordinate system. The designs made with these light sources are very close to reality. Color temperature and color rendering values are seen at the design stage with light intensity to be illuminated on the surface as a result of optical design.

In Zemax, detectors are used to analyze design results. These detectors are determined according to the design purpose. Figure 2 shows the light source and the defined detectors. Polar detector and surface detector are defined in the design. Polar detector surrounds the light source and the surface detector is at 


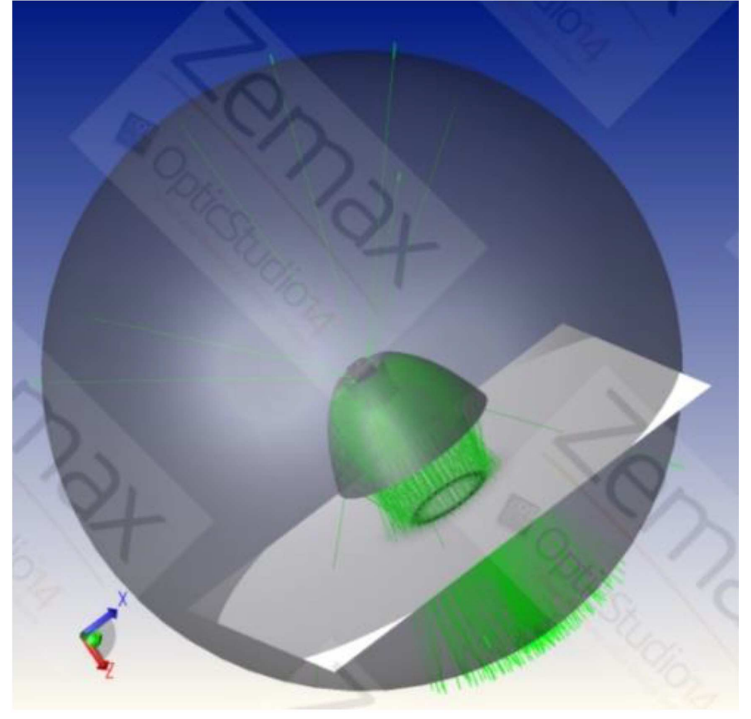

Figure 2. Light source and detectors.

a certain distance from the light source. The estimated light intensity curve of the LED light source designed with these detector applications can be calculated. The measurement results of this detector can be output as ise or .ldt file. It is possible to analyze these outputs in lighting design programs such as Dialux.

For the analysis of the lens, the optical properties of the raw material must be defined in Zemax. One of the materials in the Zemax library can be selected for this operation. If a new material is to be used, it can be analyzed by identifying its optical properties such as light refractive index and light transmittance. In addition, the surface of the lens, the surface of the design, surface roughness (sandblasting), and tissue (skates, single) to be applied to the surface must be defined.

\subsection{Evaluation of the design}

After the first analysis, it is to be evaluated whether the design meets the determined targets. An optimization process is performed to improve the design performance. In the optimization process, the target values such as smoothness, light intensity, and distribution angle are defined on the detectors. Then, values that can be changed from lens design parameters are defined as variable. The program calculates the merit function (error function) according to the objectives. The merit function shows the difference between the current performance of the design and the defined target values.

Before starting the production process for the designed lens, it was tested in the simulation by using Dialux program. The results of the analysis of the lens design from the Zemax program are taken out as a .ies or .ldt file extension. These files contain the light distribution curve provided by the lens. The light distribution curve of the lens is shown in Figure 3.

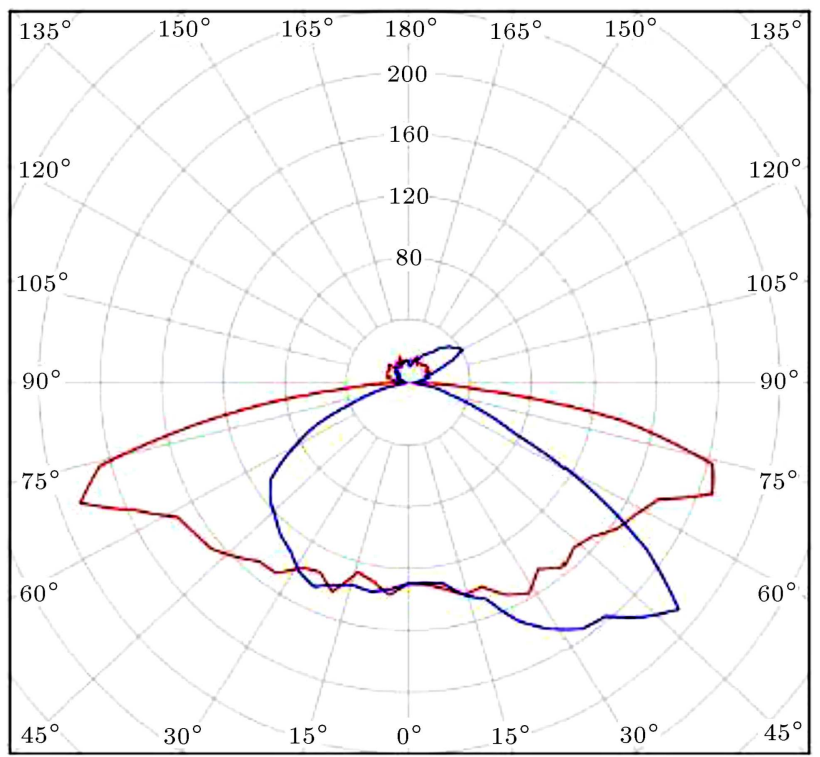

Figure 3. The light distribution curve of the lens.

In the Dialux program, the number of luminaires, the placement of the luminaires on the road, and the desired illuminance and luminance levels on the road are determined. In the DiaLux program, the M3 road system was chosen to perform the simulation test. In addition, the road information was incorporated into the test system:

- Road width: $7 \mathrm{~m}$

- Number of lanes: 2

- Asphalt: R3

- Maintenance factor: 0.89

- Average luminance coefficient (qo): 0.07

The information about the luminaires pole is given below:

- Distance between the poles: $7 \mathrm{~m}$

- Pole distance: $1.5 \mathrm{~m}$

- Light centre height: $1.5 \mathrm{~m}$

- Boom inclination: $10^{\circ}$

- Boom length: $0.65 \mathrm{~m}$

According to the designed road and illumination, the simulated lighting values resulting from the simulation created in the DIALux program are shown in Figure 4 as a color scale.

Figure 5 shows the luminance curves according to observer 1. Figure 5(b) shows the luminance curves according to observer 2 .

Table 1 shows the photometric information according to observer 1 and observer 2 . 


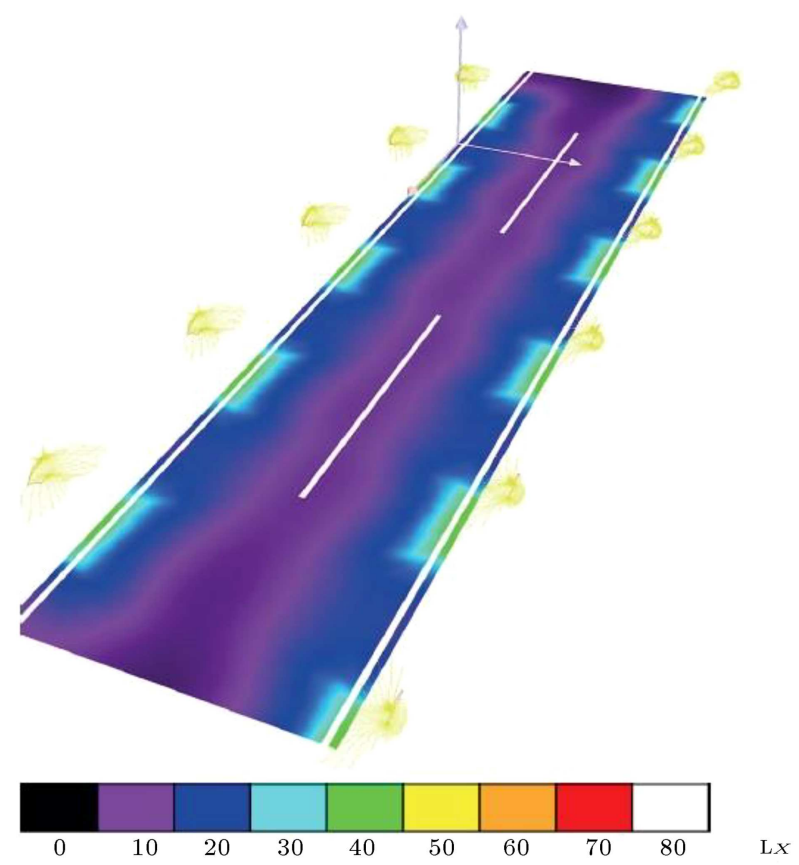

Figure 4. Lighting color scale.

\section{Experimental results and analysis}

Following the success of the tests, the mold was made for the production of the lens. The lens can be produced as needed by using this mold. In this study, 6 lenses were produced.

The other parts that make up the luminaire

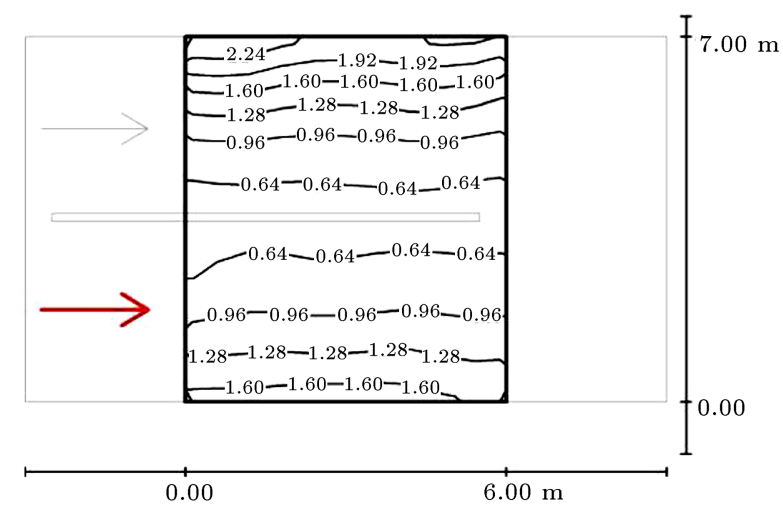

(a)
(LED lamp, safe, electrical connections, and pole) are brought together and they are finished. The final version of the luminaire is shown in Figure 6.

A lighting pole that is portable, $1.5 \mathrm{~m}$ high, and adjustable in angle was designed for testing on different roads. The features of the LED luminaire developed are given in Table 2 .

LED luminaires were mounted on the poles and, then, were tested on the road. Six luminaires are placed on the road in accordance with the standards shown in Figure 1. The luminaires on the test road are shown in Figure 7.

Photometric measurements of the LED luminaires

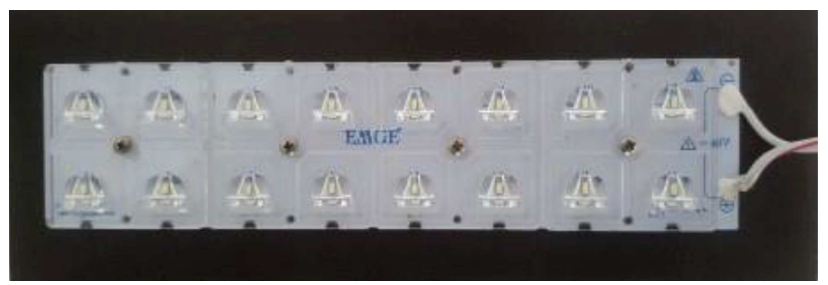

Figure 6. Final version of the luminaire.

Table 2. The features of the LED luminaire.

\begin{tabular}{lc}
\hline Power $(\mathrm{W})$ & 26 \\
Color temperature $\left({ }^{\circ} \mathrm{K}\right)$ & 4000 \\
Luminous flux $(\mathrm{lm})$ & 4000 \\
Luminous efficacy $(\mathrm{lm} / \mathrm{W})$ & 155 \\
Color rendering & $>70$ \\
\hline
\end{tabular}

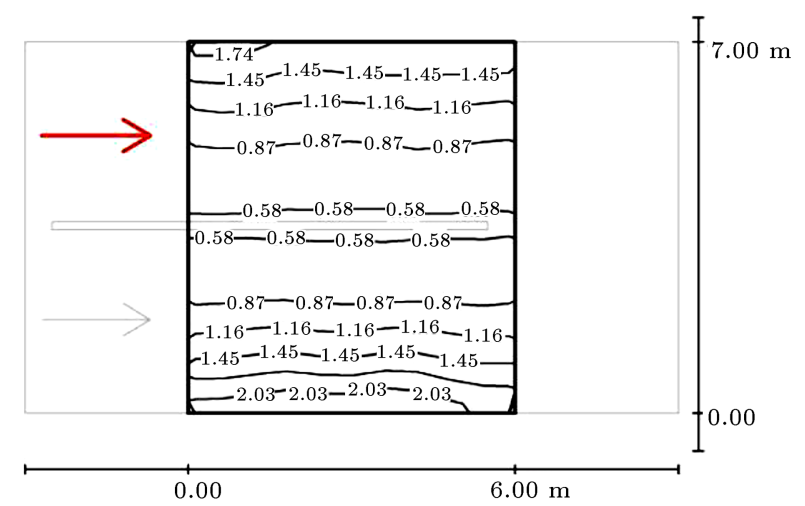

(b)

Figure 5. Luminance curves according to the observer-1 and observer-2.

Table 1. Photometric values according to observer 1 and observer 2 .

\begin{tabular}{|c|c|c|c|c|c|c|c|c|}
\hline & \multicolumn{4}{|c|}{ Observer 1} & \multicolumn{4}{|c|}{ Observer 2} \\
\hline & $\begin{array}{c}L_{m} \\
\left(\mathrm{~cd} / \mathrm{m}^{2}\right)\end{array}$ & $U_{\circ}$ & $U_{1}$ & $\begin{array}{l}T I \\
(\%)\end{array}$ & $\begin{array}{c}L_{m} \\
\left(\mathrm{~cd} / \mathbf{m}^{2}\right)\end{array}$ & $U_{\circ}$ & $U_{1}$ & $\begin{array}{l}T I \\
(\%)\end{array}$ \\
\hline Actual value according to calculation & 1.03 & 0.49 & 0.86 & 12 & 1.03 & 0.48 & 0.85 & 13 \\
\hline Required value according to class & $\geq 1.00$ & $\geq 0.40$ & $\geq 0.50$ & $\leq 15$ & $\geq 1.00$ & $\geq 0.40$ & $\geq 0.50$ & $\leq 15$ \\
\hline Fulfilled/not fulfilled & $\checkmark$ & $\checkmark$ & $\checkmark$ & $\checkmark$ & $\checkmark$ & $\checkmark$ & $\checkmark$ & $\checkmark$ \\
\hline
\end{tabular}


Table 3. A comparison of the measured values and international standards.

\begin{tabular}{|c|c|c|c|c|c|c|}
\hline \multirow{3}{*}{$\begin{array}{l}\text { International standards } \\
\text { Observer (O) }\end{array}$} & \multicolumn{2}{|c|}{$L_{m}\left(\mathbf{c d} / \mathbf{m}^{2}\right)$} & \multicolumn{2}{|c|}{$U_{o}$} & \multicolumn{2}{|c|}{$U_{1}$} \\
\hline & \multicolumn{2}{|c|}{$\geq 1.00$} & \multicolumn{2}{|c|}{$\geq 0.40$} & \multicolumn{2}{|c|}{$\geq 0.50$} \\
\hline & $\mathrm{O} 1$ & $\mathrm{O} 2$ & $\mathrm{O} 1$ & $\mathrm{O} 2$ & O1 & $\mathrm{O} 2$ \\
\hline Measured value & 1.40 & 1.64 & 0.42 & 0.38 & 0.24 & 0.22 \\
\hline $\begin{array}{l}\text { Fulfilled }(\checkmark) \\
\text { Not fulfilled }(-)\end{array}$ & $\checkmark$ & $\checkmark$ & $\checkmark$ & - & - & - \\
\hline
\end{tabular}

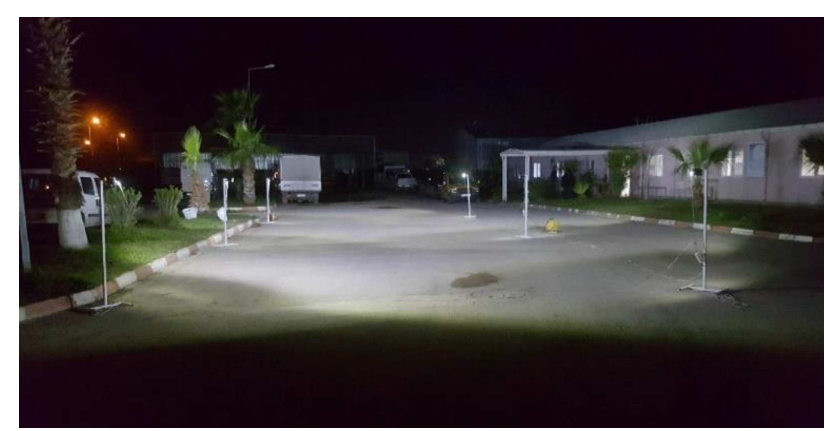

Figure 7. Luminaires on the test road.

were done by using the luminance meter. A comparison of the measured values and international standards is shown in Table 3.

One of the biggest advantages of the armature developed is that it consumes less energy while providing ideal lighting values. The way to determine the economic advantages of the LED luminaire is illuminated by the existing High-Pressure Sodium (HPS) lamps. Figure 8 shows the illumination of the road using HPS lamps.

As a result of the measurements performed, illuminating the same road with LED luminaires provides an advantage of about $37 \%$ compared to HPS. Luminance measurements of the road illuminated by HPS were performed. Comparative luminance measurements of LED and HPS lamps are given in Figure 9.

In view of this graph, it is seen that the LED lamp is much more advantageous than the HPS in terms of luminance smoothness. The road lighting with HPS lamp creates very dark and very bright areas. LED lamp is used in road lighting so that more evenly distributed lighting occurs. Thus, more uniform illumination can be provided with the LED lamp. This important factor increases the driving comfort.

\section{Conclusion}

This study developed an LED luminaire that is not only long-lasting but also enjoys high luminous efficacy, uniform luminance distribution, low glare, and costeffectiveness in accordance with international standards for M3 road class.

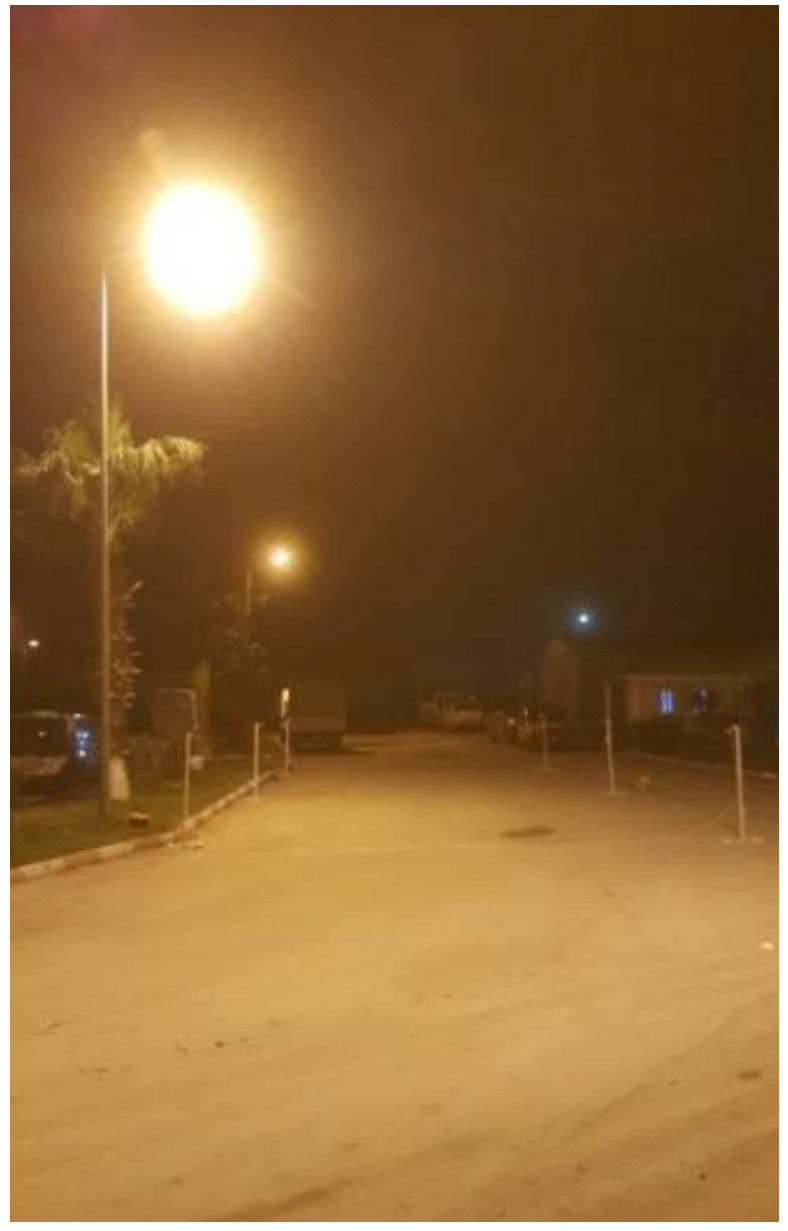

Figure 8. Lighting with HPS lamps.

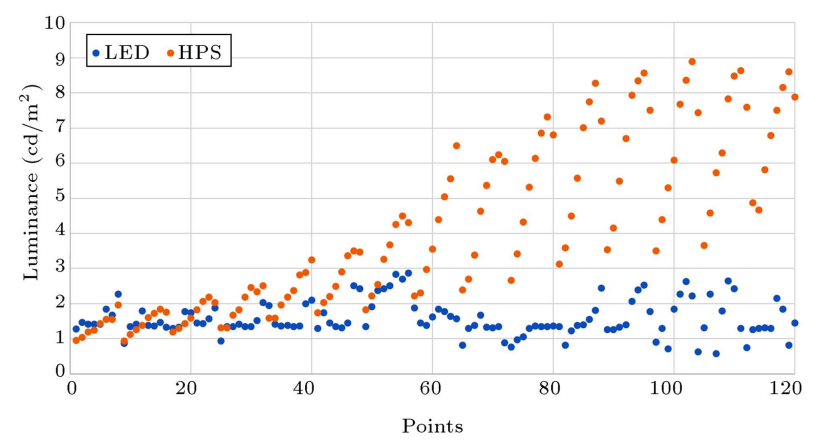

Figure 9. Comparative luminance measurements of LED and HPS lamps. 
Today, LED luminaires used in road lighting are between 45-240 W, while HPS luminaires consume 150-450 W of energy. The developed LED luminaire provides approximately $37 \%$ energy efficiency compared to HPS luminaires. This value is important for street lighting which constitutes a large part of electricity consumption.

It was found that the LED lamps provided a more homogeneous luminance distribution on the road than the existing HPS lamps. Since HPS lamps provide illumination over poles with a height of 8-12 $\mathrm{m}$ and are required to illuminate larger areas, it is difficult to provide homogeneous illumination. In the developed system, LED luminaires are at $1.5 \mathrm{~m}$ high poles so that smaller areas can be illuminated. Thus, LED luminaires provide more homogenous illumination than HPS luminaires. In this study, the overall uniformity (U0) and longitudinal uniformity (U1) of road surface luminance of the developed LED lamp are twice as good as HPS.

\section{Abbreviations}

$\begin{array}{ll}\text { LED } & \text { Light Emitting Diod } \\ \text { CIE } & \text { Commission Internationale de } \\ & \text { l'éclairage } \\ \text { HPS } & \text { High Pressure Sodium } \\ \text { TIR lens } & \text { Total Internal Reflection lens }\end{array}$

\section{References}

1. Fusheng, L., Chen, D., Song, X., et al., LEDs: A Promising Energy-Saving Light Source for Road Lighting, Asia-Pacific Power and Energy Engineering Conference, Wuhan, China (2009).

2. Lobao, J.A., Devezas, T., and Catalao, J.P.S. "Energy efficiency of lighting installations: Software application and experimental calidation", Energy Reports, pp. 100-115 (2015).

3. Reusel, K.V. "A look ahead at energy-efficient electricity applications in a modern world", Energy Climate Technology (2008).

4. Boyce, P.R., Fotios, S., and Richards, M. "Road lighting and energy saving", Lighting Research \& Technology, 41(3), pp. 245-260 (2009).

5. Pracki, P. "A proposal to classify road lighting energy efficiency", Lighting Research \& Technology, 43(3) pp. 271-280 (2011).

6. Coureaux, M.I.O. and Manzano, E. "The energy impact of luminaire depreciationon urban lighting", Energy for Sustainable Development, 17(4), pp. 357362 (2013).

7. Gutierrez-Escolar, A., Castillo-Martinez, A., GomezPulido, J.M., et al. "A review of energy efficiency label of street lighting systems", Energy Efficiency, 10(2), pp. 265-282 (2017).
8. Chenani, S.B., Maksimainen, M., Tetri, E., et al. "The effects of dimmable road lighting: A comparison of measured and perceived visibility", Transportation Research Part F: Traffic Psychology and Behaviour, 43, pp. 141-156 (2016).

9. Feng, Z., Luo, Y., and Han, Y. "Design of LED freeform optical system for road lighting with high luminance/illuminance ratio", Optics Express, 18(21), pp. 22020-22031 (2010).

10. Haans, A. and De Kort, Y.A.W. "Light distribution in dynamic street lighting: Two experimental studies on its effects on perceived safety, prospect, concealment, and escape", Journal of Environmental Psychology, 32(4), pp. 342-352 (2012).

11. Ylinen, A.M., Tahkamö, L., Puolakka, M., et al. "Road lighting quality, energy efficiency, and mesopic design LED street lighting case study", LEUKOS, 8(1), 9-24 (2011).

12. Ding, Y., Liu, X., Zheng, Z.R., et al. "Freeform LED lens for uniform illumination", Optics Express, 16(17), pp. 12958-12966 (2008).

13. Lai, M.F., Anh, N.D.Q., Ma, H.Y., et al. "The study of low-glare led table light with asymmetric secondary optical element", International Symposium on Computer, Consumer and Control, Taichung, Taiwan (2014).

14. Lai, M.F., Anh, N.D.Q., Gao, J.Z., et al. "Design of multisegmented freeform lens for led fishing/working lamp with high efficiency", Applied Optics, 54(28), pp. 69-74 (2015).

15. Lee, H.W. and Lin, B.S. "Improvement of illumination uniformity for led flat panel light by using microsecondary lens array", Optics Express, 20(S6), pp. 788798 (2012).

16. Anh, N.D.Q., Lai, M.F., Ma, H.Y., et al. "Design of a free-form lens for led light with high efficiency and uniform illumination", Applied Optics, 53(29), pp. 140-145 (2014).

17. Chen, J.J., Wang, T.Y., Huang, K.L., et al. "Freeform lens design for led collimating illumination", Optics Express, 20(10), pp. 10984-10995 (2012).

18. Wang, K., Chen, F., Liu, Z., et al. "Design of compact freeform lens for application specific light-emitting diode packaging", Optics Express, 18(2), pp. 413-425 (2010).

19. Ries, H. and Muschaweck, J. "Tailored freeform optical surfaces", Journal of the Optical Society of America A., 19(3), pp. 590-595 (2002).

20. Wang, L., Qian, K.Y., and Luo, Y. "Discontinuous free-form lens design for prescribed irradiance", $A p$ plied Optics, 46(18), pp. 3716-3723 (2007).

21. Wang, K., Liu, S., Chen, F., et al. "Freeform led lens for rectangularly prescribed illumination", Journal of Optics A: Pure and Applied Optics, 11(10), pp. 105501-105511 (2009).

22. Zhenrong, Z., Xiang, H., and Xu, L. "Freeform surface lens for led uniform illumination", Applied Optics, 48(35), pp. 6627-6634 (2009). 
23. Gimenez-Benitez, P., Miňano, J.C., Blen, J., et al. "Simultaneous multiple surface optical design method in three dimensions", Optics Express, 43(7), pp. 14891502 (2004).

24. Chen, H.C., Lin, J.Y., and Chiu, H.Y. "Rectangular illumination using a secondary optics with cylindrical lens for led street light", Optics Express, 21(3), pp. 3201-3212 (2013).

25. Wang, S., Wang, K., Chen, F., et al. "Design of primary optics for led chip array in road lighting application", Optics Express, 19(S4), pp. 716-724 (2011).

26. Lee, X.H., Moreno, I., and Sun, C.C. "Highperformance led street lighting using microlens arrays", Optics Express, 21(9), pp. 10612-10621 (2013).

27. Luo, Y., Feng, Z., Han, Y., et al. "Design of compact and smooth free-form optical system with uniform illuminance for led source", Optics Express, 18(9), pp. 9055-9063 (2010).

28. Üncü, I.S., Coşkunsu, S., Sönmez, C., et al. "CRI and GAI comparison in LED light sources using image processing", Acta Physica Polonica A, 130, pp. 379$381(2016)$.
29. Üncü, I.S. and Coşkunsu, S. "LED board error detection automation with image processing", Acta Physica Polonica A, 128, pp. 471-473 (2015).

\section{Biographies}

Ísmail Serkan Üncü received the $\mathrm{BS}, \mathrm{MS}$, and $\mathrm{PhD}$ degrees from Gazi University Ankara, in 1996, 1999, and 2004, respectively. He is currently an Associate Professor at the Department of Electrical-Electronics Engineering, Isparta University of Applied Science, Isparta, Turkey. His research interests include lighting, optical design, and image processing.

Mehmet Kayakus received the BS degrees from Marmara University İstanbul, MS, and PhD degrees from Süleyman Demirel University, Isparta, Turkey in 2006, 2010, and 2018, respectively. He is currently an Assistant Professor at the Department of Management Information Systems, Akdeniz University, Antalya, Turkey. His research interests include lighting, artificial intelligence, and image processing. 